\title{
Competencia y poder de mercado en los mercados eléctricos
}

\author{
Natalia Fabra \\ Departamento de Economía \\ Universidad Carlos III de Madrid \\ Jorge Fabra Utray \\ Comisión Nacional de Energía
}

\begin{abstract}
Resumen
Este artículo se centra en el análisis de la competencia y el poder de mercado en el Sector Eléctrico. Se repasan brevemente algunas características esenciales del suministro eléctrico que hacen que los mercados eléctricos sean particularmente vulnerables a problemas de competencia. Las implicaciones de dichas características sirven como base para identificar distintas manifestaciones del poder de mercado en los segmentos mayorista (generación) y minorista (comercialización), poniendo el énfasis en algunas manifestaciones concretas que rara vez están presentes en las discusiones regulatorias.
\end{abstract}

Palabras Clave: mercado eléctrico, competencia, poder de mercado.

Clasificación JEL: D43, L94.

\begin{abstract}
This article focuses on the analysis of competition and market power in electricity markets. We review some of the features that make electricity markets particularly vulnerable to the exercise of market power. This discussion allows us to identify how market power is reflected in wholesale electricity markets as well as in the retail segment.
\end{abstract}

Keywords: electricity markets, competition, market power.

JEL Classification: D43, L94.

\section{Introducción}

Una condición necesaria (aunque no suficiente) para el correcto funcionamiento de los mercados es la ausencia de poder de mercado. Para que los mercados cumplan su función de asignar de manera eficiente los recursos, es necesario que las empresas revelen de manera fidedigna sus costes en sus decisiones de oferta. Esto se produce cuando los agentes que concurren carecen individualmente, o en su conjunto, de una influencia determinante sobre la fijación del precio. Además, es necesario que exista libertad de establecimiento en todos los segmentos de la actividad, que las barreras de entrada y de salida no sean muy relevantes y que la presión competitiva sea suficiente para blindar los precios frente a comportamientos estratégicos de las empresas. 
Este artículo se centra en el análisis del poder de mercado como un problema para la competencia en el sector eléctrico, prescindiendo de otros problemas estructurales presentes, tales como los relacionados con la inexistencia de libertad de instalación a precios históricos en ciertas tecnologías de generación ${ }^{1}$.

Los mercados eléctricos reúnen varias características que los hace vulnerables al ejercicio del poder de mercado. La imposibilidad de almacenamiento de la electricidad, la existencia de límites de capacidad en la producción y en el transporte, la volatilidad de la demanda y su baja o nula elasticidad al precio, y la interacción frecuente entre un número reducido de empresas protegidas por barreras a la entrada, dificultan el que los mercados eléctricos respondan al paradigma competitivo.

En el mundo académico se han dedicado muchos esfuerzos al análisis e identificación de los comportamientos estratégicos en los mercados eléctricos, aportando sugerencias de mejora en el diseño de mercado tendentes a mitigarlos (tales como cambios en las reglas de la subasta, o el fomento de la contratación a plazo) ${ }^{2}$.

Pero esta preocupación no es exclusiva del mundo académico. De hecho, distintos organismos reguladores y de defensa de la competencia han puesto en repetidas ocasiones de manifiesto su preocupación por las distorsiones que el ejercicio del poder de mercado ocasiona en los mercado eléctricos. Como reconoce el regulador británico (Ofgem, 2009), "the potential for undue exploitation of market power in the electricity generation and wholesale sector has been an issue of concern to regulators since electricity markets first began to be deregulated in the 1980s."

A nivel europeo, la Energy Sector Inquiry publicada en 2007 por la Dirección General de Competencia de la Comisión Europea ${ }^{3}$, aportó evidencia sobre el ejercicio de poder de mercado en varios países europeos, entre ellos España. Los recientes casos de abuso iniciados a raíz de la Sector Inquiry y las medidas de separación de actividades o "unbundling" contenidas en el tercer paquete legislativo de la Unión Europea, reflejan una creciente incidencia y preocupación por el ejercicio del poder de mercado. Seguramente el ejemplo más reciente de ejercicio del poder de mercado en los mercados de generación de electricidad lo aporta la investigación abierta contra E.On por abuso de posición dominante (violación del Artículo 82, ahora artículo 102 del Tratado de Funcionamiento de la Unión Europea, MEMO/06/483 ${ }^{4}$. La Comisión encontró evidencia suficiente para demostrar que E.On había retirado capacidad de generación del mercado eléctrico alemán con el objetivo de elevar precios, que había tomado acciones estratégicas con el fin de dificultar la realización de nuevas inversiones, y que había operado el sistema eléctrico en detrimento de sus com-

\footnotetext{
${ }^{1}$ Para un análisis de esta cuestión, véase Fabra y Fabra-Utray (2009).

${ }^{2}$ Véanse entre muchos otros, Fabra et al. (2006), y Bushnell et al. (2008). Por ejemplo, en España, la obligación impuesta desde 2006 a los dos operadores de mayor tamaño, Endesa e Iberdrola, de subastar a terceros el derecho de uso de parte de su capacidad instalada (a través de las conocidas como "Virtual Power Plants"), responde a un intento de mitigar su poder de mercado a través de la contratación a plazo.

${ }^{3}$ Disponible en http://ec.europa.eu/competition/sectors/energy/inquiry/index.html.

${ }^{4}$ En la página web de la DG COMP, se puede consultar un listado de todos los casos de competencia en los sectores energéticos, http://ec.europa.eu/competition/antitrust/cases/index/by nace code d.html.
} 
petidores. La investigación se cerró a cambio de compromisos por parte de E.On, que aceptó desinvertir 5.000 MW en generación y sus redes de transporte.

Recientemente, el regulador británico Ofgem, ha elaborado un detallado informe en el que se diseccionan muchos de los problemas de poder de mercado presentes en el Reino Unido (Ofgem, 2009). Y, aunque el poder de mercado no es su única preocupación, sin duda es una de las que han motivado su apuesta, hecha pública muy recientemente, por un cambio radical en el diseño de su mercado eléctrico (Ofgem, 2010). Si esta transformación finalmente se concretara, sería la tercera o cuarta a la que se ha sometido al sector eléctrico británico tras la liberalización de los años noventa, seguida por diversos países, entre ellos España.

El sector eléctrico español tampoco es ni ha sido ajeno a las preocupaciones suscitadas por ejercicio del poder de mercado. Los problemas se han detectado principalmente en el segmento de la generación, pero aunque la liberalización minorista sea reciente (menos de un año), también en este segmento se están originando ya diversos problemas de competencia. A lo largo del artículo se describen algunos episodios documentados de ejercicio del poder de mercado en el sector eléctrico español.

En este artículo se discuten algunas cuestiones relacionadas con la competencia y el poder de mercado en los mercados eléctricos. Primero, se repasan algunas de las características de la electricidad relevantes para el análisis de competencia y sus implicaciones. Después, se analizan los distintos comportamientos tendentes al ejercicio del poder de mercado y posibles medidas para su mitigación en los segmentos mayoristas (generación de electricidad) y minorista (suministro de electricidad a clientes finales).

\section{Características de la electricidad relevantes para la competencia}

El análisis de competencia en los mercados de producción de electricidad no puede ignorar las características singulares de la electricidad que, como condicionantes de su oferta y demanda, tienen importantes implicaciones sobre el comportamiento estratégico de los agentes. La comprensión de sus implicaciones es por tanto fundamental para poder identificar el ejercicio del poder de mercado, así como para diseñar mecanismos eficaces de mitigación.

1. No almacenabilidad

2. Estacionalidad en la demanda y volatilidad de las energías renovables

3. Baja o nula elasticidad-precio de la demanda en el corto plazo

4. Bien perfectamente homogéneo

5. Coexistencia de diversas tecnologías de generación

6. Restricciones en le red de transporte

7. Interacción repetida en el tiempo y elevado grado de transparencia

8. Barreras a la entrada 
No almacenabilidad, volatilidad y baja elasticidad de la demanda

La energía eléctrica no es almacenable, o sólo lo es a pequeña escala y a costes muy elevados. La casi imposibilidad de almacenar la electricidad exige que producción y consumo se igualen instantáneamente en todo momento del tiempo y en todo punto de la red, porque la falta de equilibrio, por muy puntual que éste sea, generaría cortes indiscriminados en el suministro eléctrico. A este hecho se suman las fuertes oscilaciones que experimentan la demanda y las aportaciones de las energías renovables. En España, durante el día, la demanda de potencia podría aumentar sobre la que se registra por la noche en un 60\%; durante los fines de semana, la demanda llega a disminuir un $65 \%$ en energía y un $40 \%$ en potencia, sin perder la estacionalidad diaria; y durante el invierno, la demanda puede ser hasta un $15 \%$ superior a la de verano. Por su parte, las aportaciones de las energías renovables están fuertemente influidas por las condiciones atmosféricas, que ni son constantes ni en muchos casos predecibles. Por aportar algunos órdenes de magnitud, en 2009 la energía eólica en España, que contribuyó a cubrir un 13\% de la demanda total, vio cómo su aportación variaba del apenas $1 \%$ en algunas horas del año al $54 \%$ en su máximo anual.

Estas características tienen implicaciones muy importantes para el análisis de competencia. Por una parte, la curva de producción ha de seguir irremediablemente a la curva de demanda. Esto quiere decir que en el sector eléctrico no se puede recurrir a los inventarios para aplanar la curva de producción, acumulando inventarios o recurriendo a ellos cuando la demanda sea respectivamente menor o mayor a la demanda media. Por tanto, resulta necesaria la existencia de capacidad de producción suficiente para cubrir las puntas de demanda más un cierto margen de reserva, capaz de contrarrestar variaciones en el parque de generación causadas por fallos fortuitos en las centrales, en el transporte o en la distribución, o por las menores aportaciones de los recursos renovables. Tal necesidad se ve acentuada por el hecho de que los ajustes instantáneos difícilmente pueden provenir del lado de la demanda, dado que la mayor parte de ésta carece de capacidad para reducir su consumo en el corto plazo, descontados los contratos de los consumidores interrumpibles cuya potencia está computada como margen de reserva o instrumento de gestión de la demanda para el Operador del Sistema.

Las fuertes oscilaciones en la demanda y en la aportación de las energías renovables implican que, durante un gran número de horas, una parte importante del parque de generación térmico (principalmente, ciclos combinados y centrales de carbón) permanezca ocioso ${ }^{5}$, mientras que durante un número reducido de horas todas las centrales son necesarias para la cobertura de la demanda. Es decir, las condiciones de competencia varían de forma muy pronunciada de hora en hora, dependiendo de la relación entre demanda y capacidad instalada. Si bien en períodos de

${ }^{5}$ Durante 2009, los ciclos combinados y las centrales de carbón operaron a plena potencia aproximadamente durante 3395 y 2980 horas respectivamente, lo que supone en torno al 30-35\% de las horas totales del año. 
demanda baja habrá una fuerte competencia entre un gran número de centrales, en períodos de demanda alta, cuando la capacidad de todas las empresas es necesaria para la cobertura de la demanda, la competencia para la fijación del precio es muy limitada porque todas las unidades de producción serán casadas, independientemente de sus precios de oferta. La relación inversa entre capacidad existente y poder de mercado supone a su vez un desincentivo para la inversión, dificultando el que el mercado genere un margen de reserva óptimo, necesario para la gestión eficaz del sistema, que, además, contribuya a aumentar, por el lado de la oferta, la presión competitiva en los mercados.

\section{Homogeneidad del producto y diversidad de tecnologías}

La electricidad es el bien más homogéneo que se pueda concebir: resulta imposible -con independencia de las mistificaciones regulatorias o contractuales que impostan la realidad de las cosas- distinguir un kWh de otro, independientemente de quién, con qué o dónde se hayan producido. Los $\mathrm{kWh}$ ni tienen propietario ni admiten adjetivos: no existe tal cosa como un $\mathrm{kWh}$ nuclear o un $\mathrm{kWh}$ verde, o un $\mathrm{kWh}$ de ésta o aquella empresa, o de uno u otro país, porque su transporte y distribución en red impiden identificar su origen y destino. Sin embargo, detrás de la uniformidad de todos los $\mathrm{kWh}$, se esconde una compleja diversidad técnica, tecnológica y económica que es necesaria e ineludible para abastecer la totalidad de la demanda ${ }^{6}$. En España, y en general en la mayoría de países, no existe disponibilidad suficiente de una única y sola materia prima energética o energía primaria para cubrir las necesidades de producción de electricidad. Siempre es necesario recurrir a todas las fuentes energéticas disponibles, cada una de las cuales exige, a su vez, una específica tecnología para transformar la fuente primaria energética en electricidad. Ésta es la causa principal, pero no la única ${ }^{7}$, de que los medios tecnológicos para la producción de electricidad difieran y coexistan. Pero, además de inevitable, la diversidad tecnológica es deseable. La diversificación contribuye a la estabilidad de precios y a la seguridad del suministro, y permite que se cubran de forma eficiente las oscilaciones y la estacionalidad de la demanda. Así, las tecnologías con altos costes fijos y bajos costes variables operan casi continuamente a lo largo de las 24 horas del día, siendo las tecnologías de menores costes fijos y mayores costes variables las dedicadas a cubrir las variaciones en la demanda y en la disponibilidad de las ener-

\footnotetext{
${ }^{6}$ Las convenciones comerciales -contratos bilaterales físicos u otros de naturaleza semejante-que impostan la realidad física del funcionamiento del Sistema Eléctrico, no alteran la descripción realizada. Su finalidad no es otra que la búsqueda de soluciones mercantiles convencionales para la regulación del mercado de la electricidad.

${ }^{7}$ La propia regulación, que impone cotas inferiores (p.e. energías renovables) y superiores (p.e. nuclear) a la potencia instalada de cada tecnología, y la larga vida útil de las instalaciones, y el agotamiento de recursos naturales a costes competitivos, implican la coexistencia de diversas tecnologías en cada momento del tiempo.
} 
gías renovables ${ }^{8}$. (La Figura 1 muestra la curva de costes marginales de la industria, en la que las distintas tecnologías se sitúan en orden creciente en función de sus costes marginales).

FIGURA 1

ORDEN DE MÉRITO ENTRE LAS DISTINTAS TECNOLOGÍAS DE GENERACIÓN ELÉCTRICA

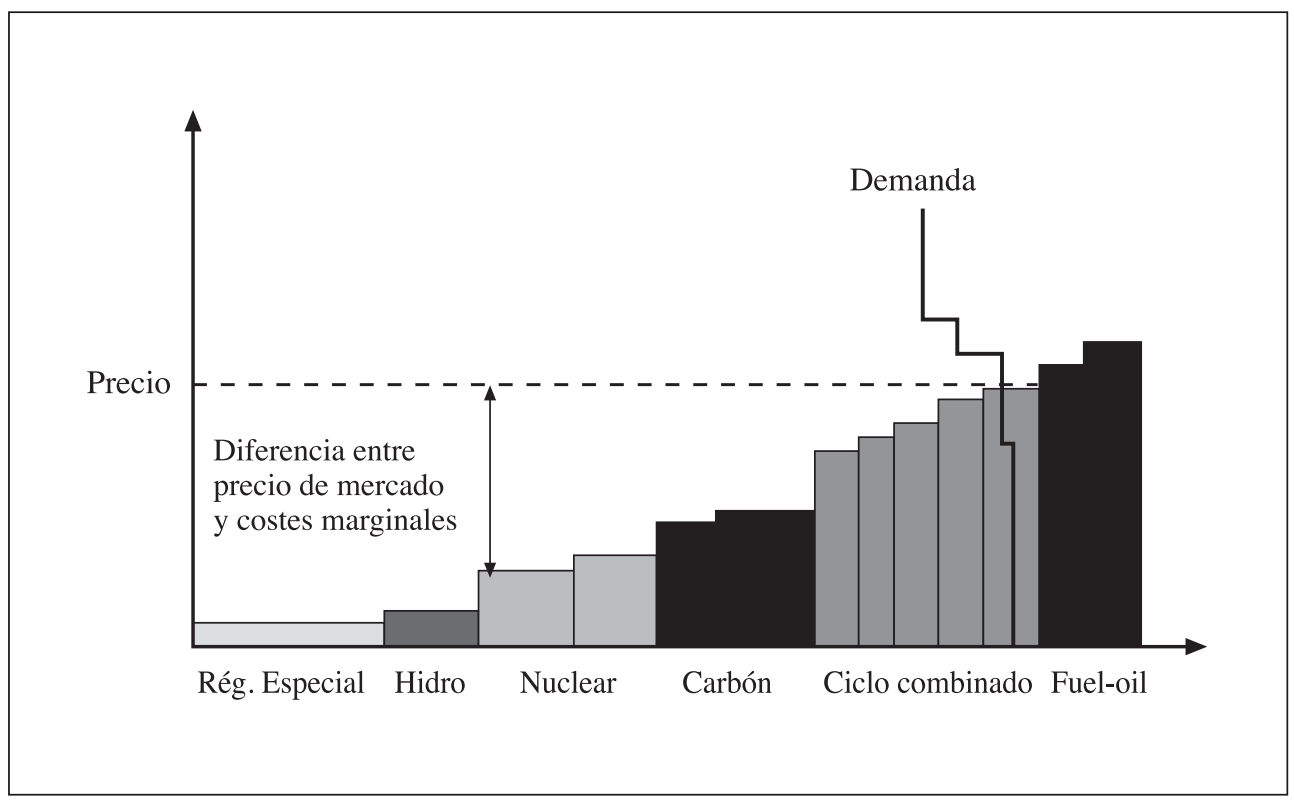

Lo anterior implica que la competencia no se establece entre todas las centrales. La rivalidad sólo se produce entre un número muy limitado de ellas, sólo entre aquellas centrales con costes marginales similares que compiten por ser casadas en el margen para satisfacer la última unidad de electricidad demandada (por ello, se denominan centrales marginales). Las centrales con costes marginales inferiores (denominadas centrales inframarginales) tendrían un coste de oportunidad muy elevado de no ser casadas, y a las centrales con costes marginales superiores (las centrales extramarginales) no les resultaría rentable ser casadas a los precios a los que están dispuestas a producir las centrales marginales. Esto no quiere decir que las centrales inframarginales o las centrales extramarginales -que en cada momento determinan

${ }^{8}$ En 2009, las energías renovables han cubierto el $26 \%$ del consumo de energía eléctrica en España. Esta cifra responde tanto a las condiciones meteorológicas favorables y a la menor demanda de electricidad, como a la intensificación en las inversiones en dichas tecnologías durante los últimos años. Ello ha implicado una menor tasa de utilización de las centrales térmicas. 
los márgenes de reserva del Sistema- sean irrelevantes en el juego de la competencia, muy al contrario. El coste marginal de las centrales extramarginales impone un límite superior a la elevación de precios de las centrales marginales, mientras que una mayor producción inframarginal genera mayores incentivos a la elevación de precios porque los mayores precios se repercuten sobre la mayor producción inframarginal ${ }^{9}$. En definitiva, el análisis de competencia tiene que tener en cuenta la compleja relación existente entre todas las tecnologías, que a su vez depende de las estructuras de propiedad corporativa y del comportamiento de la demanda, puesto que es ésta quien en última instancia determina qué tipo de centrales serán las que competirán en el margen ${ }^{10}$.

Resulta difícil reducir esta complejidad en índices agregados, como los índices de concentración, frecuentemente utilizados en los análisis de competencia ${ }^{11}$. Por ejemplo, no es equivalente en términos de competencia el que dos empresas se repartan el 50\% de la capacidad producción con un mix tecnológico muy similar o muy dispar: en el primer caso, ambas empresas estarían compitiendo en cada segmento tecnológico, mientras que en el segundo cada una se podría comportar, en cada tramo tecnológico, casi con total independencia de su rival. Para evitar esta deficiencia de los índices de concentración, a veces se recurre al cómputo de índices de concentración sobre las centrales marginales, o índices de concentración que excluyan la producción o capacidad de producción extramarginal (véase London Economics (2006)). Pero de nuevo, estas medidas, aunque complementarias entre sí, no reflejan la compleja relación existente entre las centrales que determinan la capacidad y los incentivos al ejercicio del poder de mercado. Por ello, las limitaciones de un análisis que únicamente recurra a los índices de concentración aconsejan que los análisis de competencia en los mercados eléctricos se basen en modelos que reflejen las características (físicas, institucionales y corporativas) del mercado objeto de estudio. Por ejemplo, en la literatura económica reciente se han desarrollado modelos que asumen que las empresas compiten eligiendo curvas de oferta (continuas o discretas), y la casación y retribución de las distintas unidades de oferta se realiza atendiendo a normas similares a las que imperan en los mercados eléctricos ${ }^{12}$. Este tipo de modelos tiene una mayor capacidad para predecir los comportamientos estratégicos en relación con otros modelos menos específicos, como el modelo de Cournot (o de competencia en cantidades) sobre el que se sustenta el uso de los índices de concentración.

${ }^{9}$ Es conveniente matizar que si bien las centrales que pertenecen al Régimen Especial (renovables y cogeneración) son inframarginales, no todas ellas reciben una retribución dependiente de los precios de mercado. Por ello, esta producción inframarginal no intensificaría los incentivos a ejercer poder de mercado.

${ }^{10}$ Véase García-Díaz y Marín (2003) y De Frutos y Fabra (2009) para un análisis de los equilibrios de mercado cuando las empresas difieren en su mix y capacidad de generación.

11 Borenstein, S., J. Bushnell y C. Knittel (1999) aportaron una de las primeras críticas al uso de indices de concentración, como el HHI, al análisis de la competencia en estos mercados.

12 Véanse Green y Newbery (1992) o Fabra et al. (2006), entre otros. 


\section{Restricciones en la red de transporte}

A las complejidades ya descritas, se suma una de vital importancia: desde que la electricidad se produce en las centrales de generación hasta que se suministra al cliente final, tiene que transitar por las redes de transporte de alta tensión y por las redes de distribución de baja tensión. Dependiendo de la localización de los puntos de generación y consumo y de la capacidad de la red de transporte, en algunas ocasiones se pueden crear congestiones en la red que limiten la posibilidad de importar o exportar flujos de energía de una zona a las zonas adyacentes. En presencia de restricciones en la red de transporte, las centrales que se localizan cerca de los puntos de consumo disponen de una posición de dominio que, de ser explotada, daría lugar a la elevación artificial de precios.

La existencia de restricciones técnicas tiene una especial relevancia en la delimitación del mercado relevante. Si se define el mercado relevante según los límites dentro de los cuales se produce la rivalidad entre las empresas, entonces la identificación de las restricciones de red es necesaria para la delimitación del mercado relevante, necesaria a su vez para todo análisis de competencia. Pero, al ser función de las condiciones de oferta y demanda, la definición del mercado relevante cambia a lo largo del tiempo y presenta un problema de endogeneidad: las propias empresas pueden generar congestiones de red para así limitar el tamaño del mercado.

De hecho, las empresas eléctricas españolas han sido expedientadas en diversas ocasiones por su comportamiento en el mercado de restricciones técnicas. En una decisión de Octubre de 2009, la Comisión Nacional de Competencia (CNC) ha abierto expediente sancionador contra las principales compañías eléctricas bajo la sospecha de que, entre 2004 y 2008, éstas manipularon los mecanismos de restricciones técnicas. La CNC cree que las empresas podrían haber incurrido en "un abuso de posición dominante, individual o colectivo, o en una conducta conscientemente paralela" para distorsionar el funcionamiento del mercado. En el expediente, la CNC también cita la actuación de Iberdrola en el segundo semestre de 2006, "que [al retirar demanda del mercado diario] habría provocado un aumento significativo de las restricciones técnicas en España”. La reciente decisión del Tribunal Supremo, anulando la sanción impuesta en 2004 a Unión Fenosa, Endesa e Iberdrola por "abuso de posición de dominio en los mercados de suministro eléctrico, en un contexto de restricciones técnicas", introduce sin embargo incertidumbre acerca del futuro de este tipo de expedientes. No deja de extrañar, no obstante, que el Tribunal Supremo determine implícitamente que los precios en el mercado eléctrico no han de guardar relación con los costes variables, alegando que se trata de un mercado libre. Y no deja de extrañar porque (al menos para los economistas) la quiebra de la relación entre precios y costes variables, constituye el indicio más grave de falta de competencia en los mercados. La cuestión es que no es sólo la intervención administrativa la que puede limitar la libertad de los mercados sino también -y éste es el caso- la alteración o fijación artificial de los precios por parte de los agentes que concurren en el mercado. 
Interacción repetida en el tiempo y elevado grado de transparencia

Tal y como reconocen varios autores, los mercados eléctricos reúnen ciertas características que los hacen especialmente vulnerables al mantenimiento de acuerdos colusivos:

i) generalmente existe un número reducido de competidores,

ii) la interacción entre ellos es muy frecuente, en la mayoría de los casos diaria, $y$

iii) el grado de transparencia es muy elevado (los agentes tienen acceso a datos de precios y demanda y los costes de los rivales son conocidos con un estrecho margen de error $)^{13}$.

Es bien sabido que en este contexto, las empresas pueden aprender a coordinar sus estrategias, siendo conscientes de que los posibles desvíos de una estrategia colusiva tendente a la elevación de precios se verían frustrados por la reacción competitiva de sus competidores en el momento en que se detectara el desvío. Por tanto, el análisis de competencia en los mercados eléctricos no sólo tiene que discernir si se está o no manipulando el mercado, sino además si la manipulación potencial se produce por efecto de un comportamiento estático o dinámico ${ }^{14}$.

\section{Barreras a la entrada}

Los problemas de competencia descritos con anterioridad encuentran una difícil solución a través de los propios mecanismos de mercado, porque la existencia de significativas barreras a la entrada en la actividad de generación eléctrica impiden que la amenaza de entrada pueda resultar creíble y así contribuir a disciplinar el comportamiento de las empresas incumbentes.

La existencia de barreras a la entrada en los mercados eléctricos es un hecho poco discutible. Así lo han manifestado en diversas ocasiones los diversos organismos involucrados en la supervisión y regulación del sector eléctrico en España. Tal y como señalaba el Tribunal de Defensa de la Competencia en su Informe sobre la fusión Gas Natural/Endesa (C94/05), "la existencia de activos estratégicos impide que los nuevos entrantes puedan competir en las mismas condiciones que los operadores incumbentes." Así lo corroboran también la Comisión Nacional de la Energía $(\mathrm{CNE})^{15}$ y la

\footnotetext{
${ }^{13}$ Véanse Armstrong, Cowan, y Vickers (1994), Borenstein y Bushnell (1999) y Fabra (2006).

${ }^{14}$ Véase Fabra y Toro (2005) para un análisis empírico de la colusión en el mercado eléctrico español.

15 "Informe a petición de la Comisión Nacional de la Competencia sobre la operación de concentración consistente en la adquisición por parte de Gas Natural SDG, S.A. de una participación de control sobre Unión Fenosa, S.A.” (aprobado por el Consejo de la CNE el 9 de octubre de 2008). Disponible en www.cne.es.
} 
Comisión Nacional de la Competencia $(\mathrm{CNC})^{16}$ en sus informes sobre la fusión Gas Natural/Unión Fenosa, destacando que "las barreras a la entrada más significativas son: la existencia de retrasos administrativos para la instalación de nueva capacidad, la escasa capacidad de interconexión con otros sistemas, la existencia de activos estratégicos para la generación (acceso a emplazamientos, a recursos hídricos y a combustibles, restricciones de transporte y derechos contractuales heredados), el excesivo grado de concentración empresarial y las derivadas de la integración vertical entre generación, distribución y comercialización de electricidad."

Estas barreras a la entrada, todas ellas importantes, son de muy distinta naturaleza. Por una parte, existen barreras a la entrada propias de muchas otras industrias intensivas en capital que surgen porque la toma de decisiones bajo incertidumbre implica riesgos. Dicha incertidumbre está causada por cambios en las condiciones de mercado durante la larga vida útil de los activos (oscilaciones de la demanda, cambios en el precio de los inputs, progreso técnico, etc.), y está acentuada por el hecho de que los costes de instalación de la nueva capacidad implican elevados costes fijos, en buena medida hundidos.

Por otra parte, existen barreras a la entrada propias de muchos otros mercados oligopolísticos en los que los incumbentes toman decisiones estratégicas para dificultar la entrada de competidores. Por ejemplo, y retomando de nuevo palabras de la $\mathrm{CNC}$, el "alto grado de concentración empresarial tanto por el lado de la oferta como de la demanda permite a los operadores instalados desarrollar estrategias de control de precios que pueden perjudicar a los nuevos entrantes." En la medida en que la integración vertical responde a decisiones endógenas de las empresas, ésta también se puede considerar como una barrera a la entrada estratégica, porque [los principales operadores que integran generación y comercialización] "se pueden ver relativamente indiferentes a obtener sus márgenes comerciales por el lado de la oferta o por el de la demanda, mientras que los nuevos entrantes sin integración vertical se ven enteramente expuestos al riesgo de fluctuaciones de precios." A tales barreras, hay que sumar el impacto que tienen sobre las decisiones de inversión los incentivos de las empresas incumbentes: en la medida en que exista una relación positiva entre capacidad instalada e intensidad de la competencia, las inversiones pueden conllevar una reducción de precios que afecta negativamente a la retribución de la capacidad existente (Fabra et al. (2009) y Fabra (2007)). Por ello, las empresas incumbentes tienen menores incentivos que los entrantes a expandir capacidad ${ }^{17}$, si bien éstas últimas se enfrentan a unas mayores barreras a la entrada.

Estas barreras -barreras a la entrada exógenas causadas por la aversión al riesgo, y barreras a la entrada endógenas causadas por el poder de mercado- pueden conllevar ineficiencias en la fijación de precios, debido al reforzamiento del poder de

${ }^{16}$ Expediente de la CNC C-0098/08 GAS NATURAL/UNIÓN FENOSA (aprobado por el Consejo de la CNC el 11 de febrero de 2009). Disponible en www.cncompetencia.es.

${ }^{17}$ No obstante, las empresas incumbentes mantienen un elevado número de proyectos de generación abiertos que tienden a desanimar a potenciales nuevos entrantes que perciben esos proyectos como amenaza de sobre-dimensionamiento de la capacidad instalada futura. 
mercado. También en las decisiones de inversión, pueden conllevar ineficiencias debido a probables retrasos en la incorporación de la nueva capacidad, o alteraciones en la elección óptima de las tecnologías.

Aunque hemos advertido en la introducción de este artículo que prescindiríamos de algunos problemas estructurales que afectan negativamente y de manera determinante a la calidad de la competencia en el sector eléctrico, sí conviene mencionar, en este punto, que a estas barreras hay que sumar otro tipo de barreras, las sostenidas, indirectamente y de manera sobrevenida, por la Administración: la de facto moratoria nuclear y las concesiones hidráulicas, que anulan la libertad de establecimiento en los segmentos de la generación nuclear e hidroeléctrica ${ }^{18}$. La consecuencia es que los beneficios que se generan en ambos segmentos -nuclear e hidroeléctrico-, con costes de operación, e incluso medios, muy inferiores a los precios que estas tecnologías perciben en el mercado, se ejercen desde el amparo de decisiones administrativas y de las limitaciones naturales que hacen no disputables por la competencia los citados beneficios ${ }^{19}$.

En definitiva, las características singulares de la electricidad, y sus implicaciones, hacen que el funcionamiento de los mercados eléctricos sea muy sensible al diseño de mercado y a su estructura empresarial. Para que los mercados funcionen correctamente, es necesario que se produzca competencia efectiva entre los oferentes (no sólo en el mercado, sino también en la etapa de inversión), lo cuál a su vez requiere que exista un gran número de empresas con un mix tecnológico semejante, que se disponga de capacidad de importación, y que el margen de reserva sea suficiente. Si no confluyen estas características, la elección del diseño de mercado podrá hacer poco para mitigar el poder de mercado y sus consecuencias.

\section{Competencia en el segmento mayorista (generación)}

Dadas las características de la electricidad descritas en párrafos anteriores, ¿cómo se caracteriza el comportamiento estratégico de las empresas? ¿De qué depende su viabilidad e intensidad? El comportamiento estratégico que se puede ejercer a través de las centrales hidráulicas, ¿es de la misma naturaleza que el que se ejerce a través de las centrales térmicas? ¿Se puede ejercer poder de mercado actuando sobre la demanda? A estas y otras preguntas relacionadas, se intenta dar respuesta a continuación.

${ }^{18}$ En algunos foros se alega que ciertas empresas en España están realizando fuertes inversiones en capacidad hidroeléctrica como prueba de la inexistencia de barreras a la entrada en dicho segmento. Esto sin embargo no invalida el argumento que aquí se defiende porque la capacidad de aprovechamientos hidráulicos, agotada o no, no es infinita, y si no es ahora, se saturará antes o después. Además, independientemente de este hecho, lo que es incuestionable es que el desarrollo de nueva capacidad hidroeléctrica con costes medios inferiores a su alternativa térmica ya ha sido agotado, y que, en cualquier caso, las inversiones hidráulicas nuevas tendrán rentabilidades muy inferiores a las de las centrales existentes, cuyos costes de inversión ya han sido recuperados a través de retribuciones reguladas, que son las que disponen de los emplazamientos mas rentables.

19 Véase Fabra y Fabra-Utray (2009), y Fabra Utray y Mednik (2008) para un análisis de las implicaciones que ello tiene sobre los equilibrios retributivos en el Sector Eléctrico. 


\subsection{Ejercicio del poder de mercado vía oferta}

Con algunas excepciones, y de forma genérica, los mercados de generación eléctrica se organizan en torno a mecanismos de subastas: los generadores declaran, a través de sus curvas de oferta, los precios mínimos a los que están dispuestos a producir cada $\mathrm{kWh}$, al igual que los demandantes (grandes consumidores, comercializadores, o titulares de las unidades de bombeo), que declaran los precios máximos a los que están dispuestos a consumir cada $\mathrm{kWh}$. El subastador, conocido como el Operador del Mercado, establece el orden de preferencia económica entre las pujas, casa oferta y demanda, y determina el precio que será ingresado o pagado, por todas las unidades despachadas, según sean de oferta o de demanda.

El comportamiento maximizador de los agentes les llevará a ofertar sus unidades de producción teniendo en cuenta el impacto de sus pujas sobre la cantidad producida y el precio de mercado, dado el previsible comportamiento de sus rivales. En este cálculo, las empresas se enfrentan a la siguiente disyuntiva: elevar sus pujas por encima de los costes marginales implicará una pérdida de producción, pero que podrá ser al menos en parte, compensada por el incremento resultante en el precio de mercado. Sobre la curva de demanda residual a la que se enfrenta una empresa (que se construye restando de la demanda agregada, para cada nivel de precios, la cantidad que están dispuestos a producir los rivales), se puede identificar la pérdida de producción asociada a cada incremento del precio, y así los efectos sobre los beneficios de la elevación de precios ${ }^{20}$-véase la Figura 2.

Como en otros mercados, existe una relación positiva entre el tamaño de las empresas y sus incentivos a la elevación de precios ${ }^{21}$. Ello es así porque las empresas de mayor tamaño se enfrentan a curvas de demanda residual más elevadas, y probablemente también menos elásticas, debido a que sus rivales tienen menor capacidad para expandir su producción en respuesta al aumento de precios. Además, el beneficio percibido por las empresas de mayor tamaño también será mayor, porque el aumento en el precio lo percibirán a través de toda su producción. Por ello, y aún en situaciones en las que las empresas de mayor tamaño no sean en sentido estricto pivotales (es decir, imprescindibles para la cobertura), tendrán una mayor capacidad e incentivos a beneficiarse del ejercicio del poder de mercado.

Los efectos, al menos en el corto plazo, de tales comportamientos estratégicos son de doble naturaleza. Por una parte, se produce una elevación de precios y por lo tanto un aumento en el excedente de los productores en detrimento del de los consumidores; por otra, se pueden producir ineficiencias productivas (y por tanto, una

${ }^{20}$ Es importante matizar que lo que a menudo se refiere como "retirada de capacidad" no es más que la forma más extrema de elevación de precios (es "como si" se ofertara la "capacidad retirada" a un precio infinito). Sin embargo, si bien los efectos de la elevación de precios o de la retirada de capacidad pueden ser similares, ambas opciones pueden tener distintas implicaciones en cuanto a su detección, y por tanto ser preferidas por unos agentes bajo unas u otras circunstancias.

${ }_{21}^{21}$ No obstante, no siempre se verifica una relación positiva entre concentración y poder de mercado. Véanse Borenstein et al. (1999) y García-Díaz y Marín (2003). 
FIGURA 2

\section{PODER DE MERCADO A TRAVÉS DE CAMBIOS ESTRATÉGICOS} EN LA OFERTA

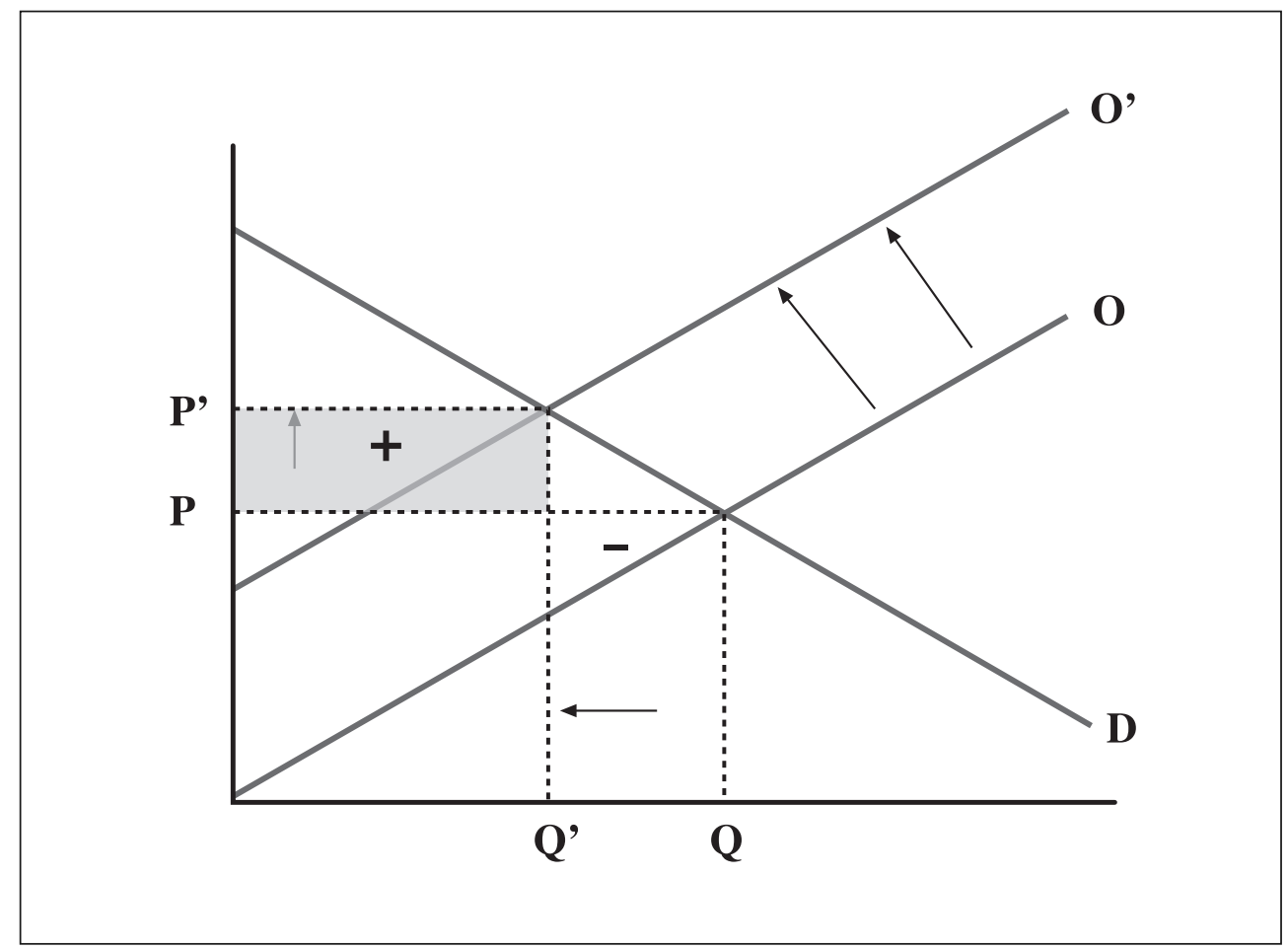

disminución en el bienestar económico) porque la reducción en la producción de las empresas que ejercen poder de mercado sea sustituida por la producción de unidades de mayores costes, propiedad de las empresas que se comportan como tomadoras de $\operatorname{precios}^{22}$.

\section{El comportamiento estratégico de las centrales hidráulicas}

La descripción hecha en los párrafos anteriores sobre el comportamiento estratégico de las empresa eléctricas se refería al que se ejerce a través de las centrales térmicas (principalmente, ciclos combinados, centrales de carbón, y centrales mixtas

22 De forma adicional, como resulta estándar, se podría producir una pérdida de bienestar económica si la elevación del precio produjera una reducción en el consumo. Sin embargo, dicha pérdida de bienestar no se produce si la demanda es inelástica al precio (en este caso se produciría una distribución desigual del excedente), o si los consumidores no pagan el precio que se negocia en el mercado spot. 
gas-fuel oil), para las que el coste de oportunidad de no producir es igual al margen entre el precio y el coste marginal al que renunciarían de permanecer paradas. Ésta es precisamente la razón por la que, en los mercados eléctricos competitivos, las ofertas de estas centrales se hagan a coste marginal. Sin embargo, lo mismo no puede decirse de la producción de las centrales hidroeléctricas con capacidad de regulación, para las que el coste de oportunidad de no producir es menor o nulo: al ser almacenable, el agua puede ser utilizada para generar electricidad en otro momento.

Por lo tanto, la primera pregunta que debe hacerse es ¿cuál es el coste relevante de generación de la hidráulica regulable que determina su comportamiento óptimo? El coste relevante no es su coste marginal de generación. Si las centrales hidráulicas regulables ofertaran su producción a coste marginal, serían casadas en todas las horas (punta, llano y valle) y sus reservas quedarían agotadas en las primeras 2000-3000 horas del año, convirtiéndose el resto del año en "meras centrales fluyentes" con muy poca potencia. Por consiguiente, de no tener las centrales hidroeléctricas regulables un comportamiento estratégico, perderían su mayor aportación al sistema (gestionando la energía producida de esta manera, las centrales hidráulicas regulables aportan su mayor valor al sistema). Es decir, la mayor aportación de valor al sistema de las centrales hidroeléctricas regulables se produce cuando en sus ofertas se autoexcluyen del mercado en determinadas horas para colocar sus 2000-3000 horas de funcionamiento en los mercados de operación y de restricciones y en las puntas de demanda, en las que los precios del mercado son mayores y maximizan sus ingresos. Por ello, la retirada de capacidad hidroeléctrica del mercado para su utilización en momentos posteriores, no puede ser considerada como una estrategia tendente a la elevación artificial de los precios contraria al interés general sino, muy al contrario, como un comportamiento necesario para alcanzar el óptimo social en su explotación.

En otras palabras, es eficiente que las centrales hidroeléctricas regulables maximicen sus ingresos inter-temporalmente y oferten su energía al coste de oportunidad, que es superior a su coste marginal. Este coste viene dado por el máximo precio que podrían haber obtenido de haber colocado dicha energía en otro mercado (intradiario, operación, restricciones, etc.) o en otro momento dentro del horizonte temporal de su ciclo hidráulico.

Por otro lado, el coste de oportunidad no es el mismo para todos los períodos ni para todos los mercados. Es el coste de la energía sustituida, en caso de que existan excedentes de potencia térmica; el coste de la energía no servida, en caso de que la última central de oferta sea pivotal o el coste de un desequilibrio general o local del sistema, en el caso de que estemos en un mercado de restricciones resuelto bajo monopolio. Considerar que en estas circunstancias existe un precio de referencia sobre el cual cabría suponer ejercicio de poder de mercado implicaría establecer un límite implícito (secreto) contrario a la transparencia y seguridad jurídico-regulatoria. La solución, por lo tanto, en estos casos, no pasa por establecer procesos sancionadores por abuso de poder de mercado, sino por incorporar cambios regulatorios que orienten un comportamiento predecible de los operadores, compatible con los intereses generales del sistema. 
No obstante lo anterior, la integración bajo una misma empresa de la gestión de los recursos hidráulicos y la propiedad de otras tecnologías inframarginales, como la nuclear, puede introducir distorsiones en el uso óptimo del agua. Ello es así porque dicha empresa maximiza los beneficios de todas sus centrales, y no sólo las hidráulicas. En particular, en vez de querer colocar el agua en aquellos momentos donde su valor es máximo (generalmente, cuando se producen las puntas de demanda), puede tener incentivos a colocarla en aquellos períodos en los que su impacto sobre el precio que perciben el resto de las centrales es menor. Es decir, moviendo el agua de las puntas al valle, el precio de mercado sube más en las puntas, precisamente cuando la producción inframarginal es mayor, de lo que se reduce en el valle, incluyendo en este cálculo la propia pérdida de valor del agua.

\subsection{Ejercicio del poder de mercado vía demanda}

Salvo excepciones, generalmente sólo se presta atención al poder de mercado que se ejerce actuando sobre la oferta: elevando precios, retirando capacidad, o en el caso de la producción hidroeléctrica, alterando el perfil de producción en relación con el que resultaría de la optimización hidrotérmica ${ }^{23}$. Sin embargo, existe un modo alternativo de poder de mercado, con consecuencias similares, y que sin embargo ha pasado hasta ahora desapercibido: el que se ejerce alterando la demanda. Aquí nos detendremos en analizar los incentivos a alterar la demanda vía exportaciones, y vía bombeo, bajo el diseño actual del mercado eléctrico español. Otras vías que permitieran aumentar con fines estratégicos la demanda podrían tener efectos similares.

\section{Exportaciones}

La exportación, al constituir una mayor demanda en el sistema nacional, supone una escalada en el precio de casación (de acuerdo con las vigentes reglas de casación). Se trata de un efecto perverso de las exportaciones de electricidad contra-intuitivo desde las experiencias de otros sectores productivos: los españoles pagamos para que nuestras empresas exporten a los países vecinos. Y no se trata sólo de un efecto sobre el reparto de excedentes entre consumidores y empresas. También puede implicar ineficiencias productivas y por tanto una reducción en el bienestar general (que se suma a la causada por la elevación de precios).

Constatado este sorprendente efecto de las exportaciones de electricidad sobre los precios interiores, en este punto nos limitaremos a analizar la posible utilización de las exportaciones como instrumento de poder de mercado.

Análogamente con el poder de mercado ejercido a través de la oferta, que ha sido descrito en párrafos anteriores, en lugar de restringir la oferta para que otros agen-

${ }^{23}$ Véanse Bushnell (2003) y Arellano (2007). 
tes marquen precios con unidades de mayor coste marginal, las exportaciones se prestan a que la demanda pueda ser amplificada de forma estratégica con el mismo objetivo. En ambos casos, el incentivo al ejercicio del poder de mercado deriva del efecto de la subida de precios sobre la producción inframarginal de la empresa y, por tanto, el incentivo es mayor cuanto mayor sea ésta. La contrapartida es distinta, pero los efectos sobre la eficiencia productiva similares: si bien una empresa que eleva precios renuncia al margen de beneficios sobre la producción perdida, la empresa que exporta de forma estratégica (por debajo de los precios que pudiera obtener en el mercado nacional) pierde el margen entre el precio nacional y el precio de exportación -véase la Figura 3. En el caso del poder de mercado vía oferta, la ineficiencia productiva deriva del hecho de que otra empresa reemplaza la producción a través de unidades de mayores costes; en el caso del poder de mercado vía demanda, la ineficiencia deriva del hecho de que en el país exportador se abastece la mayor demanda incurriendo en costes superiores a los de las unidades que dejan de producir en el país importador y esta demanda no paga el coste de su suministro. Por último, a diferencia del poder de mercado vía oferta, el poder de mercado vía demanda se

FIGURA 3

\section{PODER DE MERCADO A TRAVÉS DE CAMBIOS ESTRATÉGICOS EN LA DEMANDA}

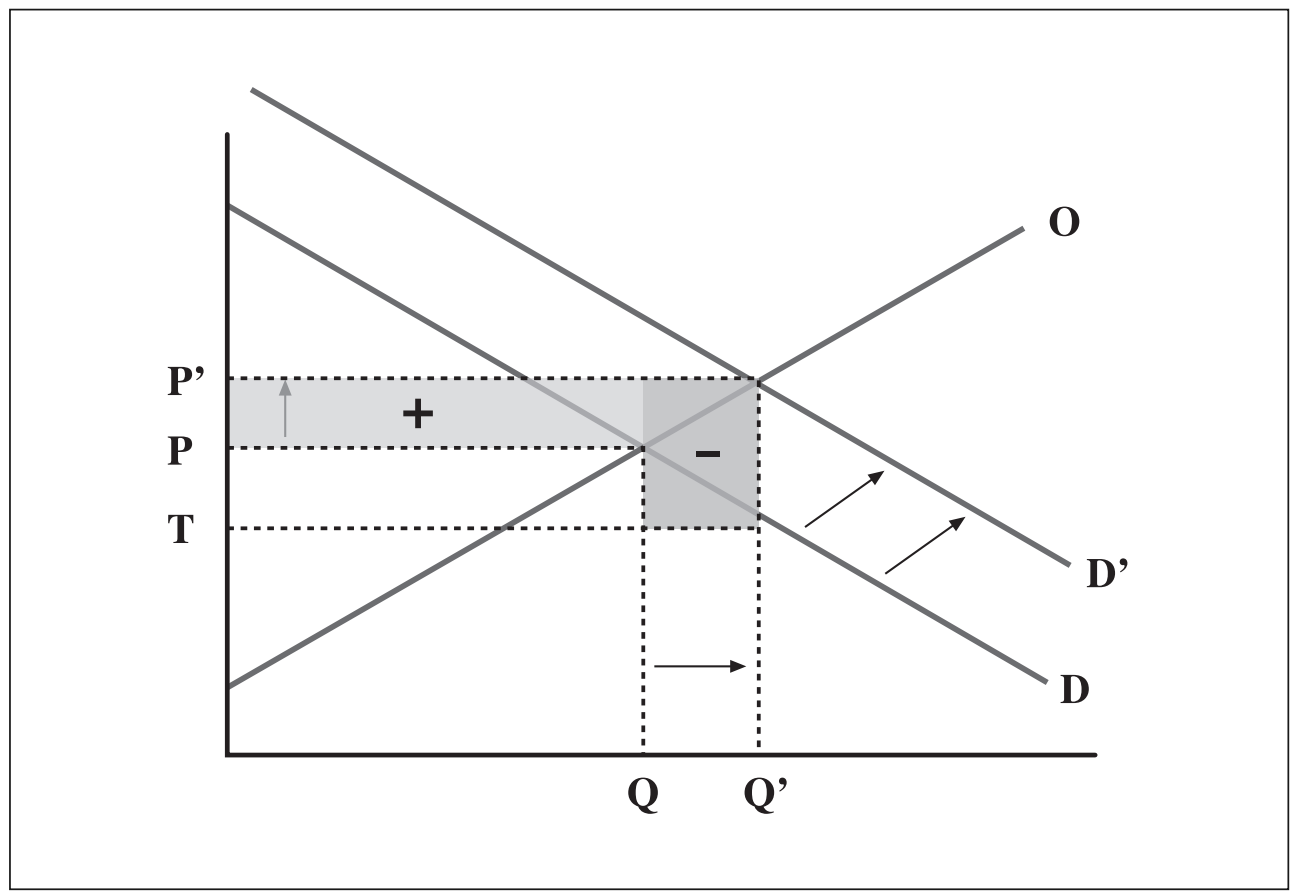

Nota: $\mathrm{T}=$ precio en el país importador. 
puede ejercer sin disponer de unidades que marcan precios, que son las que generalmente se consideran con la capacidad de alterar los precios de mercado. Además, se trata de un comportamiento estratégico difícilmente detectable por parte de los organismos de supervisión.

\section{Bombeo}

El problema que presenta el bombeo es semejante al que presentan las exportaciones: el bombeo es propiedad de empresas que perciben cualquier incremento de los precios ocasionado por una demanda extra como una retribución adicional de sus unidades de generación ${ }^{24}$. A diferencia de las exportaciones, en vez de arbitrar precios entre países, se trata de arbitrar precios entre períodos, pero los efectos sobre los precios y la eficiencia son de similar naturaleza.

El bombeo aporta elevadas ganancias de eficiencia porque permite aplanar la curva de demanda térmica y cambiar el valor del agua, bombeando en periodos de precios bajos para turbinarla en periodos de precios altos, cuando los costes de las tecnologías a las que sustituye son más elevados. El problema es que los incentivos estratégicos pueden distorsionar el uso eficiente del bombeo, así como desplazar a los grandes consumidores del valle, dificultando sus aportaciones a la gestión de la demanda del Sistema.

La demanda que genera el bombeo exige el acoplamiento de una central adicional que pasará a marcar un mayor precio que percibirán todas las unidades acopladas en ese mismo momento. Por tanto, puede ocurrir que una empresa tenga incentivos a desoptimizar el bombeo para llevarlo a aquellas horas en las que su propia producción inframarginal sea mayor, y por tanto mayor el beneficio que percibe por efecto de la subida del precio.

\subsection{Mitigación del poder de mercado en el segmento mayorista}

Los incentivos a ejercer poder de mercado se pueden mitigar, e incluso anular, reduciendo el volumen de producción cuya retribución dependa de los precios de mercado. Ciertamente, no se trata de vaciar el mercado, sino de todo lo contrario: la liquidez del mercado, que está asociada con su volumen de contratación, es una característica irrenunciable si se quiere que éste opere de manera eficiente. Para mitigar los incentivos a la elevación de precios basta con que las empresas estratégicas tengan el mismo interés en que los precios suban, como en que bajen: es decir, que su posición neta, o la diferencia entre lo que venden y lo que "compran" en el mer-

${ }^{24}$ Cuantitativamente, el bombeo en España puede suponer una demanda añadida al valle cercana a 3.000 MW y puede ser ofertado siguiendo una curva muy elástica. En 2009, el bombeo supuso $3.736 \mathrm{GWh}$ de mayor demanda, que representa un $1,4 \%$ de la demanda total. 
cado, sea pequeña. Esto se puede conseguir a través de la integración vertical entre la generación y la comercialización (que sin embargo tiene otros efectos negativos), o a través de contratos por diferencias que implican que la empresa recibirá un precio dado ${ }^{25}$ por una cantidad exógena (es decir, no dependiente del resultado del mercado) que luego se liquida por diferencias con el precio del mercado. Dado que toda divergencia entre la cantidad fija y la cantidad efectivamente vendida en el mercado recibe o paga (según su signo) el precio del mercado, se preservan los incentivos marginales necesarios para la consecución de la eficiencia, al tiempo que se reduce el beneficio de la elevación de precios puesto que ésta sólo afecta a la retribución de la posición neta -véase la Figura 4.

\section{FIGURA 4}

\section{EL EFECTO DE LOS CONTRATOS (X) SOBRE LOS INCENTIVOS A EJERCER PODER DE MERCADO}

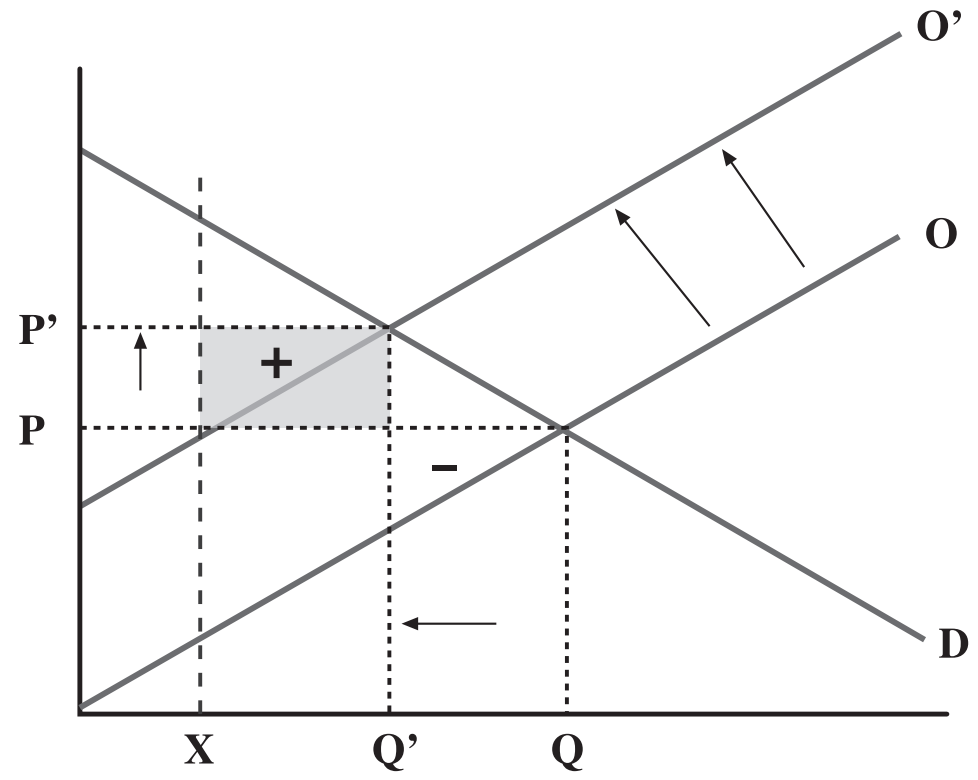

${ }^{25}$ El nivel de dicho precio no altera los incentivos de las empresas, porque éste constituye un ingreso hundido. Sin embargo, es un elemento crucial, porque es el que en definitiva determina gran parte de la retribución de la empresa. En algunas ocasiones, se ha optado por fijar dicho precio de forma administrada, como en el caso de los CTC's, de forma similar a como se hizo en el caso de los vesting contracts que se utilizaron en el inicio de la liberalización en el Reino Unido. Pero no hay ninguna razón que excluya que dicho precio también sea producto de la competencia, tal es el caso de las VPPs, o las CESUR, o por razones distintas, de la alternativa regulatoria que se propone en este artículo. 
Éste es el fundamento teórico que ha justificado el fomento de la contratación a plazo en los mercados eléctricos ${ }^{26}$, o el uso de las Subastas Virtuales de Capacidad (VPP's) como instrumentos de la política de defensa de la competencia. También explica porqué los Costes de Transición a la Competencia (CTC's) en España, que se liquidaban por diferencias, disciplinaron (a pesar de las imperfecciones en su diseño) el comportamiento estratégico de los agentes durante su período de vigencia.

\section{Competencia en el segmento minorista (comercialización)}

En aplicación de las directivas de la CE y de la propia Ley del Sector Eléctrico, en España se ha implantado recientemente una nueva regulación que implica la liberalización completa del suministro de electricidad. Desaparecen las tarifas eléctricas, excepto para aproximadamente el 30\% de la energía consumida (aquella consumida por los hogares, con potencias inferiores a $10 \mathrm{~kW}$ ), que tienen el derecho (que no la obligación) de acogerse a la denominada Tarifa de Último Recurso (TUR) que, además, constituye una tarifa aditiva de los precios del mercado. El resto de los consumidores (PYMES y grandes consumidores eléctricos, con potencias superiores a $10 \mathrm{~kW}$ ) no pueden acogerse a tarifa alguna, por lo que han de negociar con los denominados "comercializadores libres" los precios y las condiciones de su suministro eléctrico.

En los próximos párrafos, se realiza una reflexión sobre el valor añadido que aportan las comercializadoras en el suministro eléctrico, el margen existente para que la competencia entre ellas sea efectiva, y las posibles distorsiones competitivas que podrían introducir las comercializadores que suministran a los consumidores sujetos a la TUR (denominadas Comercializadoras de Último Recurso, o CUR).

\section{1. ¿Qué valor añadido aportan las comercializadoras al suministro de electricidad?}

En los mercados en competencia, dado el comportamiento de los rivales, las empresas eligen el precio, las características, y la calidad de sus bienes o servicios para maximizar sus beneficios. Cuando la calidad del servicio prestado es irrelevante en relación con su contenido, y las características del bien están dadas, la competencia se encauza a través de cambios en los precios. Si por el contrario existe margen para alterar calidad y características, las empresas tienen incentivos a hacer sus productos más heterogéneos con el objetivo de reducir la competencia buscando nichos de mercado en los que el número de rivales es menor. En definitiva, dependiendo de las circunstancias de cada mercado, la competencia puede ser positiva en la medida en que promueva la reducción de precios, la elevación de la calidad del bien o del servicio que se suministra, o el incremento en la variedad y gama de productos.

${ }^{26}$ El artículo pionero en esta área es el de Allaz y Vila (1993). Para su aplicación a los mercados eléctricos, véanse entre otros, Wolak (2007) y De Frutos y Fabra (2009). 
A diferencia de la mayoría de bienes y servicios, la calidad y continuidad del suministro son determinadas por el sistema en su conjunto en una compleja sucesión de hechos concatenados que, de forma instantánea y coordinada, comienza en la generación de electricidad, continúa por su transporte a través de las redes de alta tensión, y finaliza en la distribución o entrega física del bien al consumidor final. Por tanto, las características físicas de la electricidad que llega a los puntos de consumo son las mismas independientemente de la identidad del comercializador o de las condiciones económicas que éste haya acordado con el consumidor. En otras palabras, sin capacidad para alterar la calidad del suministro eléctrico, la única dimensión en la que los comercializadores pueden diferenciarse de sus rivales es la puramente contractual. Y en esta dimensión sólo se puede incluir el precio y su estructura temporal (desde un precio fijo a uno variable en tiempo real). La oferta de otros bienes y servicios (como el gas, la telefonía o servicios de reparaciones o de seguros) acompañando a las ofertas de electricidad, responde al comportamiento estratégico de las empresas, y en la mayoría de las ocasiones sólo contribuyen a hacer opaca para el consumidor la competitividad de sus ofertas de electricidad y a dificultar la entrada de potenciales competidores.

Dichas diferencias contractuales pueden justificar el que distintos consumidores opten por distintos comercializadores, aún a pesar de que las características físicas de la electricidad que reciban de unos y otros, sean idénticas. Ello puede ser positivo en la medida en que haya margen para que los precios efectivamente se reduzcan, o porque se responda mejor a las preferencias de los consumidores (por ejemplo, diferentes estructuras de precios dan mayor o menor cobertura a consumidores con distintas actitudes ante el riesgo, o la venta conjunta del suministro eléctrico con otros servicios o bienes pudiera reducir ciertos costes a los consumidores). Sin embargo, no existe unanimidad en torno a si estas ventajas que pueden aportar los comercializadores justifican su mera existencia. Por un lado, Joskow (2000) defiende que en el sector eléctrico existe poco margen para que los comercializadores independientes aporten suficiente valor añadido, y aboga por la alternativa de que los consumidores adquieran la electricidad a través de un "servicio básico de electricidad" que, ofrecido por los distribuidores, consistiría en la venta de la electricidad al precio del mercado mayorista más un cierto margen regulado. Por otro lado, Littlechild (2002) confía en que la competencia entre los comercializadores jugará un papel importante en la liberalización del sector eléctrico, tanto como mecanismo de transmisión de información como fuente de valor añadido ${ }^{27}$.

\section{2. ¿Será efectiva la liberalización del segmento minorista?}

Una cuestión es que la regulación permita la competencia entre comercializadoras para el suministro de electricidad a los clientes finales, y otra bien distinta es que

\footnotetext{
${ }^{27}$ Fabra Utray (2004, pp. 229-244) también aporta una discusión sobre la cuestión.
} 
la competencia entre éstas sea efectiva. Por ello, cabe preguntarse: ¿serán competitivos los precios en el mercado minorista? Es decir, ¿reflejarán los precios del mercado de generación que constituyen el coste en el que incurren los comercializadores para abastecer sus demandas?

Existen ciertos indicios que apuntan a la conclusión contraria: existen dificultades de consolidación para nuevos entrantes en la actividad de comercialización debido, entre otras, a la integración vertical entre generación y comercialización de electricidad y entre los negocios gasista y eléctrico de las empresas incumbentes; los consumidores se enfrentan a ciertos costes de cambio de suministrador y no son siempre conscientes de los precios que pagan por el suministro; y el margen para la diferenciación del producto y la aportación de valor añadido por parte de los comercializadores es escasa, como ya se ha discutido. Sin que haya una competencia efectiva, los precios del suministro "minorista" no sólo incorporarán los márgenes sobre los precios competitivos que pudieran derivarse del poder de mercado existente en el mercado mayorista, sino también los márgenes obtenidos por el poder de mercado que pueda verificarse en el propio mercado minorista o de venta final.

\subsection{Las Comercializadoras de Último Recurso (CUR) y la competencia minorista}

Más allá de la polémica sobre la conveniencia de poner a los comercializadores en competencia o no, lo que sí parece claro es que si se eliminan las posibles diferencias contractuales porque se trata de un suministro regulado, como el suministro de último recurso, es decir, con unos precios y una estructura horaria de precios dada, y la imposibilidad de venta conjunta con otros servicios, ¿qué pueden aportar las Comercializadoras de Último Recurso (CUR), figura sobre la que se ha basado la liberalización del segmento minorista? Las CUR no sólo no aportan valor al suministro de electricidad, sino que son al mismo tiempo, altamente burocráticas y perturbadoras de las relaciones de los consumidores con el resto de los agentes del sistema (generadores, distribuidores, comercializadores y operadores del mercado).

Para analizar si las CUR son una fuente adicional de distorsiones en el segmento minorista, a continuación se analizan dos elementos importantes: la existencia de costes de cambio de suministrador de los consumidores que opten por abandonar la TUR y el acceso privilegiado a la información de la que podrían gozar las CUR.

\section{Costes de Cambio de Suministrador}

Existen costes de cambio ${ }^{28}$ cuando el consumidor tiene que incurrir en ciertos costes al cambiar de comercializador, que no hubiera tenido que realizar permaneciendo con su comercializador actual. Dependiendo de su naturaleza, dichos costes

\footnotetext{
${ }^{28}$ En la terminología inglesa, son los denominados switching costs.
} 
se pueden clasificar en distintos tipos. Primero, el cambio de suministrador genera costes de búsqueda porque requiere invertir tiempo para la búsqueda de un nuevo comercializador, para la adquisición de información relativa a precios, estructura de las tarifas, métodos de pago o productos ofrecidos, y para la comparación de dicha información con ofertas alternativas ${ }^{29}$. Además, una vez seleccionado el nuevo comercializador, los consumidores se enfrentan a costes de transacción, como los requisitos y el tiempo necesarios para formalizar el nuevo contrato, así como la espera para que éste se haga efectivo. El cambio de comercializador puede además provocar costes contractuales, como la pérdida de ciertas ventajas creadas por programas de fidelización, o políticas de descuentos que sólo se hacen efectivos tras un cierto período de relación contractual. Por último, la incertidumbre en cuanto a si el servicio prestado por el nuevo suministrador será adecuado (atención al cliente, transparencia en la facturación, continuidad del suministro, etc. ${ }^{30}$ puede provocar los denominados costes psicológicos, contribuyendo a desincentivar el cambio aún a pesar de que un comercializador alternativo ofrezca una mejor oferta.

La existencia de costes de cambio de suministrador genera dos incentivos contrarios en la fijación de precios ${ }^{31}$. Por una parte, existe un incentivo a la reducción de precios para así capturar una amplia base de clientes. Por otra, los costes de cambio de suministrador crean inercia en las decisiones de contratación, reduciendo la elasticidad de la demanda y creando así un incentivo al aumento de precios. La importancia de ambos incentivos, y por tanto el efecto de los costes de cambio sobre la política de precios de una empresa, dependerá del tamaño de su base de clientes: el incentivo a la reducción de precios para la captación de clientes será más fuerte para las empresas que no dispongan todavía de una amplia base de clientes; las empresas con una mayor base tendrán un mayor incentivo al aumento de precios, dado que la pérdida potencial por no captar nuevos clientes será menor que el aumento de los ingresos obtenidos a través de sus clientes cautivos.

Dichos resultados teóricos han sido corroborados por diversos estudios empíricos que utilizan datos de los mercados de gas y electricidad en el Reino Unido (véase Giuletti, Waddams y Waterson (2005)). Una de sus conclusiones destaca que las empresas con una mayor base de clientes (típicamente, las empresas incumbentes en cada una de las quince áreas en las que se dividió el país), a pesar de cobrar precios más elevados, han mantenido una mayor cuota de mercado, y por ambos factores, también mayores beneficios. Se ha verificado a su vez que el valor

29 Un informe encargado en 2001 por el regulador británico, OFGEM, revela la importancia de dichos costes en los mercados energéticos: la mayoría de los consumidores domésticos de electricidad no son capaces de nombrar suministradores alternativos al incumbente, y sólo uno de cada tres consumidores es capaz de realizar comparaciones de precios correctamente.

${ }^{30}$ Aunque el comercializador no pueda alterar la calidad del suministro, el consumidor puede no ser consciente de ello.

31 Klemperer (1995) discute los mecanismos principales a través de los cuales los costes de cambio afectan a la competencia, y el informe OFT (2003) ofrece un resumen de los trabajos teóricos sobre costes de cambio de suministrador. 
de un cliente es muy superior a su coste de captación. Por ejemplo, mientras que el coste de capturar a un nuevo cliente es de aproximadamente 60 libras esterlinas, en procesos de fusiones recientes (PowerGen-TXU, London Electricity-SEABOARD) se ha estimado el valor de cada cliente cautivo en aproximadamente 280-310 libras esterlinas.

Estas cuestiones resultan relevantes para la discusión que aquí nos ocupa. Los clientes sujetos a la TUR, siempre que no opten por abandonarla, no constituyen una base de clientes en el sentido utilizado en párrafos anteriores: al estar sus precios regulados, no cabe la posibilidad de que la CUR eleve los precios futuros para aprovecharse de dichos consumidores cautivos. Sin embargo, la masa de consumidores a tarifa sí puede aportar una ventaja competitiva para la empresa encargada del suministro a tarifa porque los consumidores que opten por salir de la tarifa, se enfrentarán a menores costes de cambio si contratan con la misma empresa en el mercado libre que si lo hacen con uno de sus competidores. Atendiendo a la clasificación anterior, podemos apuntar que:

- Los costes de búsqueda del consumidor que abandone la tarifa serán menores si contrata con el comercializador libre integrado con una CUR, dado que al estar ya en contacto con él, el acceso a la información sobre los precios, estructuras tarifarias y productos ofrecidos será más fácil.

- Los costes de transacción serán también menores, dado que al existir ya un contrato entre ambas partes, se evita la necesidad de traspasar información sobre los datos necesarios para la contratación.

- Los costes contractuales no pueden jugar ningún papel en esta cuestión, dado que el suministro regulado no puede incluir ni programas de fidelización, de descuentos, o similares ${ }^{32}$.

- La existencia de costes psicológicos puede favorecer también al comercializador integrado con la CUR, dado que el consumidor puede percibir que la calidad del suministro será la misma si permanece con una empresa del mismo grupo, y dudar acerca de la calidad del suministro contratado con una empresa que desconoce.

\section{Acceso a la información de los clientes}

Las conclusiones anteriores, relacionadas con la existencia de costes de cambio de suministrador, se ven reforzadas si se tiene en cuenta que el comercializador libre que está integrado con una CUR puede disponer de mayor información acerca de los consumidores de la que puedan disponer sus rivales. Esta información, que incluye datos sobre los perfiles de consumo, consumos históricos, pólizas de contra-

32 A no ser que con éste se realice conjuntamente, ver la venta de otros servicios a precios no regulados, cuestión que por su evidente contradicción, se descarta. 
tación, etc., puede permitir al comercializador realizar ofertas más ajustadas a las necesidades de sus potenciales consumidores, adquiriendo así una ventaja competitiva frente a comercializadores sin acceso a dicha información. Es decir, la ventaja para captar al consumidor que abandone la tarifa no sólo proviene de los menores costes que percibe el consumidor al cambiar al comercializador perteneciente al mismo grupo de la CUR, sino que además proviene de la superioridad de la información a la que accede este último.

La solución a las posibles distorsiones que pudiera generar el acceso a información privilegiada ha sido la creación de bancos de datos a los que, en teoría pueden acceder todos los agentes de mercado. En la práctica, sin embargo, se ha comprobado que esto no asegura el derecho de acceso de todos los agentes a la información en condiciones de igualdad. Prueba de ello es la investigación que la Comisión Nacional de la Competencia (CNC) mantiene abierta sobre prácticas restrictivas de la competencia en el sector eléctrico español. En el marco de esta investigación, la CNC ya impuso una multa de 36 millones de euros a Endesa, Iberdrola, Hidrocantábrico, Gas Natural y E.On por posibles prácticas anticompetitivas en el suministro de electricidad a clientes finales (contrarias al artículo 1 de la Ley de Defensa de la Competencia y el artículo 101 del Tratado de Funcionamiento de la Unión Europea). Dichas prácticas consistieron en la suspensión temporal a terceros, por parte de las distribuidoras de estos grupos empresariales, del acceso telemático a los datos necesarios para gestionar el cambio de compañía suministradora de los consumidores finales. En noviembre del mismo año, la CNC ha llevado a cabo inspecciones por sorpresa en la sede de la patronal eléctrica, UNESA, a la que también ha incluido en la investigación. La conducta objeto de incoación consistió en "la existencia de una estrategia de coordinación en el sector eléctrico tendente, entre otros, a la obstaculización del cambio de suministrador de electricidad."

\subsection{Mitigación del poder de mercado en el segmento minorista}

Para mitigar los problemas de competencia detectados en el segmento minorista así como eliminar las distorsiones que introduce la mera existencia de las CUR, se podría considerar un enfoque alternativo, basado en la completa desaparición de las tarifas eléctricas y una mínima regulación de las ofertas de los comercializadores. Bajo esta alternativa, serían los propios comercializadores y no el Ministerio los que ofrecieran a todos los consumidores, entre sus diferentes ofertas libremente configuradas con las características, plazos y precios que consideraran convenientes, la opción de un contrato básico consistente en el suministro de electricidad al precio que resultara de la media ponderada de los precios horarios del mercado mayorista verificados en el plazo del correspondiente contrato.

De esta manera, todos los consumidores tendrían la opción de acogerse a cualquiera de las ofertas imaginativas y competitivas que los comercializadores les presentaran -que sin duda surgirían del juego de la competencia- y entre ellas, la suscripción 
de un contrato básico de suministro en el que los comercializadores prestarían a los consumidores un servicio básico con un pass-through puro de los precios del mercado mayorista correspondiente al perfil de su consumo ${ }^{33}$.

En su implementación sería necesario establecer un periodo transitorio para todo aquel consumo de baja tensión que careciera de contadores horarios, considerando los precios de mercado que correspondan al perfil de consumo característico de este nivel de tensión. De esta manera, las tarifas de energía quedarían completamente eliminadas sin dejar desprotegido a ningún grupo de consumidores.

La transparencia y sencillez de este planteamiento de la comercialización aportaría a los consumidores la calidad y las garantías necesarias exigibles a todo entorno competitivo basado en el ejercicio de la libertad de elección por los consumidores de suministradores en competencia.

Una ventaja adicional pero fundamental: la existencia de un servicio básico (como el antes apuntado), a disposición de todos los consumidores independientemente de su potencia contratada, constituiría, por sí mismo, un estímulo a la competencia porque los consumidores tendrían una alternativa en el caso de que los comercializadores tendieran a elevar el resto de sus ofertas por encima de los precios de mercado. De esta manera la competencia se beneficiaría de la característica que la hace posible: la transparencia.

\section{Conclusiones}

El potencial ejercicio del poder de mercado y sus implicaciones -junto con otros problemas de carácter estructural relacionados con la ausencia de libertad de instalación en las principales tecnologías inframarginales de generación- no tiene que ser dejado de lado a la hora de diseñar los mecanismos regulatorios que rigen los mercados eléctricos. Tanto la lógica económica como la práctica han puesto de manifiesto la importancia de comprender cómo las características especiales de la electricidad pueden aumentar la capacidad y los incentivos de las empresas eléctricas a manipular estos mercados en detrimento de la eficiencia productiva y de una distribución equitativa de los excedentes de la actividad entre empresas y consumidores.

En el segmento mayorista (generación de electricidad), la elevación artificial de las pujas de oferta o retirada física de algunas unidades de producción, favorece el aumento de precios con los que se retribuye toda (o gran parte) de la producción que en cada momento contribuye a la cobertura de la demanda; si este efecto compensa la posible pérdida de producción sufrida por la empresa o empresas que lleven a cabo dicha estrategia, ejercer poder de mercado será rentable. También, a través de cambios estratégicos de la demanda que induzcan un aumento artificial de la demanda de exportación o de una utilización estratégica de la demanda de bombeo, las empresas

${ }^{33}$ Productos similares ya se utilizan con éxito en diversos países, como Noruega (véase von der Fehr y Hansen, 2009). 
eléctricas pueden aumentar sus beneficios, porque la mayor demanda implica una elevación de los precios de mercado que retribuye la totalidad de la generación.

El segmento minorista (comercialización de electricidad) tampoco ha sido ajeno a problemas de competencia. La imposibilidad de diferenciar un $\mathrm{kWh}$ de otro y el nulo papel que las comercializadores pueden jugar en la calidad y en la seguridad del suministro eléctrico, hacen que la competencia entre ellas sólo se pueda canalizar a través del nivel de precios. Sin embargo, la fuerte inercia en las decisiones de consumo causada por la existencia de costes de cambio de suministrador (que resultan muy elevados en relación con los potenciales ahorros en forma de menores precios), mitigan la competencia entre comercializadores, haciendo que aguas abajo se incorpore un nuevo margen al precio de la electricidad sin compensación real para los consumidores. A ello hay que añadir las asimetrías de partida que benefician a las empresas incumbentes, que dificultan la entrada de nuevos competidores. En línea con otros países, la existencia de un contrato básico de suministro que implicara un pass-through puro de los precios del mercado mayorista (sobre los que se podrían desarrollar instrumentos de mitigación de su volatilidad) podría introducir un estímulo a la competencia, al constituir una alternativa para los consumidores en el caso de que las comercializadoras tendieran a elevar sus ofertas por encima de los precios de mercado.

\section{Referencias bibliográficas}

[1] ALLAZ, B. y VILA, J. L. (1993): "Cournot competition, forward markets and efficiency", Journal of Economic Theory, 59 (1), pp. 1-16.

[2] ARELLANO, S. (2007): "Market power in mixed hydro-thermal electric systems", mimeo, Pontificia Universidad Católica de Chile.

[3] ARMSTRONG, M.; COWAN, S. y VICKERS, J. (1994): Regulatory reform: Economic analysis and the British experience, MIT Press.

[4] BORENSTEIN, S. y BUSHNELL, J. (1999): "An empirical analysis of the potential for market power in California's electricity market.” Journal of Industrial Economics, 47,3 .

[5] BORENSTEIN, S.; BUSHNELL, J. y KNITTEL, C. (1999): "Market power in electricity markets, beyond concentration measures." The Energy Journal 20, 4.

[6] BUSHNELL, J. (2003): "A mixed complementarity model of hydro-thermal electricity competition in the Western U.S.", Operations Research, 51, 1, pp. 81-93.

[7] BUSHNELL, J.; MANSUR, E. y SARAVIA, C. (2008): "Vertical arrangements, market structure, and competition: An analysis of restructured U.S. electricity markets", American Economic Review, 98 (1), pp. 237-266.

[8] DE FRUTOS, M. A. y FABRA, N. (2009): "How to award forward contracts: the case of electricity markets", mimeo, Universidad Carlos III de Madrid.

[9] FABRA, N. (2006): "El funcionamiento del mercado eléctrico español bajo la Ley del Sector Eléctrico" en "Del monopolio al mercado. La Comisión Nacional de la Energía: diez años en perspectiva" Editorial Thomson, Civitas. 
[10] FABRA, N. (2007): "La electricidad: mercados, inversiones y garantía de suministro", Economía Industrial, 364, pp. 63-75.

[11] FABRA, N. y FABRA UTRAY, J. (2009): "Un diseño de mercado para el sector eléctrico español”, Papeles de Economía Española, 121, pp. 141-158.

[12] FABRA, N. y TORO, J. (2005): "Price wars and collusion in the Spanish electricity market" International Journal of Industrial Organization 23, 3-4, pp. 155-181, disponible en www.eco.uc3m.es/nfabra.

[13] FABRA, N.; DE FRUTOS, M. A. y VON DER FEHR, N-H. (2009): "Market design and investment incentives", mimeo, Universidad Carlos III de Madrid.

[14] FABRA, N.; VON DER FEHR, N-H. y HARBORD, D. (2006): “Designing electricity auctions", RAND Journal of Economics, 37 (1), pp. 23-46.

[15] FABRA UTRAY, J. (2004): “Un mercado para la electricidad: ¿Liberalización o regulación?". Madrid, Marcial Pons.

[16] FABRA UTRAY, J. y MEDNIK, G. (2008): “Diversidad de tecnologías, costes y precios en el mercado de electricidad" en "Energía y Regulación” Madrid, Thomson, Civitas.

[17] GARCÍA DÍAZ, A. y MARÍN, P. (2003): "Strategic bidding in electricity pools with short-lived bids: An application to the Spanish market", International Journal of Industrial Organization, 21, pp. 201-222.

[18] GIULIETTI, M.; WADDAMS, C. y WATERSON, M. (2005): “Consumer choice and competition policy: a study of UK energy markets,” Economic Journal, 115 (506), pp. 949-968.

[19] GREEN, R. y NEWBERY, D. (1992): "Competition in the British electricity spot market,” Journal of Political Economy, 100 (5), pp. 929-53.

[20] JOSKOW, P. (2000): "Why do we need electricity retailers? or Can you get it cheaper retail?," disponible en http://econ-www.mit.edu/faculty/pjoskow/papers.

[21] KLEMPERER, P. (1995): “Competition when consumers have switching costs: An overview with applications to Industrial Organization, Macroeconomics, and International Trade," Review of Economic Studies, 62 (4), pp. 515-39.

[22] LITTLECHILD (2002): “Competition in retail electricity supply," Cambridge Working Papers in Economics 0227.

[23] LONDON ECONOMICS (2006): "Structure and performance of six european wholesale electricity markets in 2003, 2004, and 2005," disponible en http://www.londecon.co.uk/.

[24] OFGEM (2009): “Addressing market power concerns in the electricity wholesale Sector," disponible en www.ofgem.gov.uk.

[25] OFGEM (2010): Project discovery: options for delivering secure and sustainable energy supplies, Reference number: 16/10, disponible en www.ofgem.gov.uk.

[26] OFT (2003): "Switching costs", Office of Fair Trading, Department of Trade and Industry (UK), Economic Discussion Paper 5.

[17] VON DER FEHR, N-H. y HANSEN, P. V. (2009): "Electricity retailing in Norway," EUI-RSCAS Working Papers 4, European University Institute.

[28] WOLAK, F. (2007): "Quantifying the supply-side benefits from forward contracting in wholesale electricity markets,” Journal of Applied Econometrics, 22, pp. 1179-1209. 
